\title{
A study of Identification and Antifungal Susceptibility Pattern of Candida species Isolated from Various Clinical Specimens in a Tertiary care Teaching Hospital, Chinakakani, Guntur, Andhra Pradesh, South India
}

\author{
Naseema Shaik, Uma Penmetcha*, Ramesh Babu Myneni, \\ Padmaja Yarlagadda and Susmitha Singamsetty
}

\author{
Department of Microbiology, NRI Medical College \& General Hospital, \\ Chinakakani, Mangalagiri Mandal, Guntur District, Andhra Pradesh, India \\ *Corresponding author
}

\section{Keywords}

Candida albicans, Nonalbicans candida, Risk factors, chrom agar, antifungal resistance.

\section{Article Info}

Accepted: 07 June 2016 Available Online: 10 July 2016

\section{A B S T R A C T}

The global incidence of Candidiasis has risen steadily over the past few decades. Candida species are now among the most common health care -associated pathogens. Most of the studies show that the predominant species $C$. albicans has been replaced by non albicans Candida with the use of antifungal agents. As various species differ in susceptibility pattern to the newer antifungal agents, antifungal susceptibility test should be performed before administration of antifungal agents. To isolate and identify different Candida species in various clinical specimens, to know the predominant species, to study the risk factors, to compare the advantage of rapid method such as use of Chrom agar over conventional methods for identification and confirmation of Candida species and to detect their antifungal susceptibility pattern. All the clinical samples collected from cases of candidiasis were processed initially using blood agar, MacConkey bile salt lactose agar and SDA with chloramphenicol. Cultures that are identified as candida species were processed using standard yeast identification protocol and chrom agar. Patient detailed clinical history including risk factors was noted. Antifungal susceptibility testing of the yeast isolates was assessed using agar disc diffusion method according to CLSI guidelines. The antifungal drugs used for disc diffusion method are amphotericin B, Nystatin, fluconazole, Voriconazole, ketaconazole \& clotrimazole. A total of 150 Candida isolates were subjected to speciation \& antifungal susceptibility testing. Candida isolates were present in $94(62.6 \%)$ males and $56(37.3 \%)$ females. Prolonged use of antibiotics was the major risk factor 41 (27.3\%) followed by Biomedical devices 32 (21.3\%), Medical causes 21(14\%), Diabetes mellitus $17(11.3 \%)$, Trauma 14 (9.3\%), Surgical causes 11 (7.3\%), Pregnancy 7(4.7\%), birth asphyxia $5(3.3 \%)$ and HIV 2 cases $(1.3 \%)$ respectively. A total of $90(60 \%)$ isolates were obtained from urine, respiratory samples $26(17.3 \%)$, Blood 16 (10.7\%), High vaginal swabs 14 $(9.3 \%)$, wound swabs $4(2.7 \%)$ respectively. In our study Non albicans candida species are more in number over C. albicans. Among Non albicans Candida, C.tropicalis isolation is more, 86 (57.33\%). The sensitivity and specificity of CHROM agar was found to be $100 \%$ for C.albicans. For C.tropicalis the sensitivity was $100 \%$ \& specificity was $95.3 \%$. All the isolates of Non albicans Candida were susceptible to Amphotericin B, Nystatin, Voriconazole, Clotrimazole, Itraconazole\& Fluconazole. But some species of NAC like C.guilliermondii and C.lipolytica which showed $40 \%$ and $33.4 \%$ resistance. $22 \%$ of strains of C.tropicalis showed resistance against Fluconazole. C.famata showed complete resistance to fluconazole, clotrimazole, Itraconazole, whereas C.dubliniensis \& C.guilliermondii showed $33.4 \%$ and $40 \%$ resistance to Fluconazole. C.albicans showed $100 \%$ susceptibility to Amphotericin B \& nystatin followed by Ketoconazole $(83.3 \%)$, Voriconazole (76.6\%), Itraconazole (75.8\%), Clotrimazole (71.6\%) and Fluconazole $(63.3 \%)$ respectively. Isolation of non - candida albicans species was more than Candida albicans. The predominant species isolated in our study was $C$.tropicalis. Chrom agar candida medium was found to be useful in identification of candida species. All candida isolates were sensitive to amphotericin $\&$ nystatin The antifungal resistance was more in the non albicans species than in Candida albicans. Hence there is a need for speciation, susceptibility testing \& periodic surveillance of candida species. 


\section{Introduction}

The incidence of Nosocomial fungal infection has been increased due to advancement in medical management, and change in patient profile (Fridkin SK. et al., 2006). The candida species are a part of normal flora of the alimentary tract and mucocutaneous membranes of humans. Candida species that are a part of normal flora can invade tissues and cause life threatening diseases in patients whose cell mediated immunity is decreased by disease or iatrogenic intervention (Odds FC.1988)

Due to variable clinical presentation of Candida infections, it becomes very important to identify these pathogens from all the clinical specimens. C. krusei and C. glabrata are known for their innate resistance to fluconazole (Chander J., 2009). The genus Candida includes several species implicated in human pathology such as $C$. albicans, C. tropicalis, C. parapsilosis, $C$. glabrata, C. krusei, C. lusitaniae, C. kefyr, C. guilliermondii and C. dubliniensis (Sulivan DJ. et al., 1995)

The increase in the incidence of Candida species over the past two decades is significant and non-albicans Candida species continue to replace Candida albicans at most of the clinical sites like bloodstream infections (Chander J., 2009). Since 1995, Candida species have become the fourth most common cause of nosocomial bloodstream infection and are associated with a crude mortality rate of $39 \%$, which is the highest mortality rate associated with any cause of nosocomial bloodstream infections. In intensive care units (ICUs), infection with Candida species is the third most frequent cause of nosocomial bloodstream infection and is associated with a crude mortality rate of $47 \%$ (Anurag Malani, et al., 2005).
The incidence and associated mortality due to Candidaemia can be influenced by several factors including characteristics of the population at risk, standard of the healthcare facilities available, distribution of candida species and prevalence of resistance. Hence, epidemiological information available for one centre or geographic region may not be applicable to others (Hobson RP., 2003)

Candidiasis is a primary or secondary infection involving a member of the genus Candida. The clinical manifestations of disease are extremely varied, ranging from acute, sub acute and chronic to episodic. Involvement may be localized to the mouth, throat, skin, scalp, vagina, fingers, nails, bronchi, lungs, or the gastrointestinal tract, or become systemic as in septicaemia, endocarditis, and meningitis. Candidaassociated denture stomatitis is a very common inflammatory process affecting about $60 \%$ of the subject's carrier of a prosthesis. Oral carriage of Candida species was significantly higher in diabetic patients compared with healthy individual (Salerno C. et al., 2011; Soysa C.et al., 2006).

The frequency of vaginal candidiasis during pregnancy was found to be $38 \%$, in which $27 \%$ were symptomatic and $11 \%$ were asymptomatic group. Increased ratio of infection was observed in multigravida and diabetic women (Parveen N.et al., 2008).

Conditions that increase the rates of genital Candida colonization are known risk factorsfor candiduria including diabetes mellitus, antibiotic use, immunosuppressive therapy, prolonged hospitalization, extremes of age, and female sex (Uma Chaudhary. et al., 2009). Recent studies indicate that Candida may be isolated from the hands of $15-54 \%$ of health care workers in the intensive care unit setting and that the strain of Candida carried on the hands may be 
shared by infected patients (Pfaller, 1995).

Recently, the incidence of life-threatening fungal infections has been the rise, and rapid identification of pathogenic yeasts and detection of polyfungal infections has become mandatory. The most widely used medium for the isolation of Candida species and other fungi is Sabouraud's dextrose agar. As the identification of yeasts may take several days, employing chromogenic media can help to reduce the time of isolation and identification as well as the detection of mixed cultures by $48-72$ hours.

Little or no similar work has been carried out in Medical Colleges more so in Andhra Pradesh. So, the present study has been taken up to isolate and identify the Candida species using conventional \& rapid methods. Such identification gives us prognostic \& therapeutic significance, allowing in the selection of appropriate antifungal agents by clinicians and to prevent the emergence of drug resistance.

\section{Materials and Methods}

A cross sectional study was carried out in the Department of Microbiology, NRI Medical College and General Hospital (NRIMC \& GH), Chinakakani, Guntur (Dt) Andhra Pradesh. This is a tertiary care hospital and Super speciality centre. The study was undertaken for a period of 1 year from $1^{\text {st }}$ January 2014 to $30^{\text {th }}$ December 2014.

The specimens were collected under strict aseptic precautions from clinically suspected cases of candidiasis in MICU, SICU, NICU, PICU, CCU, KTU, wards and outpatient departments of NRI General Hospital. Detailed clinical history of all Patients was recorded.

Sample Size: A total of 150 Candida species isolated from various clinical specimens were taken for the study.

\section{Inclusion Criteria}

All patients male and female of all age groups were taken into study and all the specimens showing Candida isolation in two consecutive samples were included in the study.

\section{Specimens Collection}

The specimens for the study were collected from the clinically suspected cases of candidiasis under strict aseptic precautions. The various clinical specimens collected were throat swabs, ear swabs, vaginal swabs, CSF, sputum, blood, pus, nail scrapings etc. Test tube containing two swabs or sterile bottles was used to collect each sample. The specimens were transported immediately to the laboratory. One of the swabs was used for direct examination and the other for the culture. The specimens were processed by using a set of preliminary tests like wet mount, Gram stain, and culture on SDA with Chloramphenicol and incubated at $25^{\circ} \mathrm{C}$ for 2 days to 3 weeks. Cultures were identified by the colony characters and by gram's stain. Once the colonies were confirmed speciation done by the following methods (Segal E. et al., 2007; Rippon JW. 1988), (Milne, 2007).

a. Germ Tube Test: (Reynolds Braude Phenomenon) (Milne LJR. 2007), (Forbes BA. et al., 2007)

b. CHROM (HICROME) Agar Candida.

c. Corn meal agar inoculation (Dalmau plate culture)

d. Sugar Fermentation Test (Arunaloke Chakrabarti . et al.,2008)

e. Sugar Assimilation Test(Arunaloke Chakrabarti. et al., 2008),(Larone DH., 2002)

f. Urease test . 
Antifungal susceptibility testing of the yeast isolates was assessed using the agar diffusion method ${ }^{16}$ according to CLSI guidelines. The discs were supplied by HiMedia, Mumbai. Muller-Hinton agar supplemented with $2 \%$ glucose and $0.5 \mu \mathrm{g} / \mathrm{ml}$ methylene blue was used for the sensitivity testing. The addition of the glucose speeds up growth of the yeasts and the addition of the methylene blue enhances edge-definition of zones. Disc diffusion method was used in the present study. The antifungal agents used for disc diffusion method are: Amphotericin B -100 units,

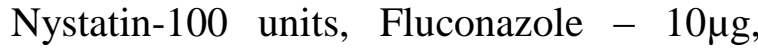
Clotrimazole-10 $\mu \mathrm{g}$, Voriconazole $-1 \mu \mathrm{g}$, Ketaconazole-10 $\mu \mathrm{g}$, Itraconazole- $10 \mu \mathrm{g}$. ; the diameters of the zones of inhibition obtained were compared with the standard zones interpretive breakpoints published by CLSI M44-A guidelines.(CLSI., 2009) The following quality control strains were obtained from PGIMER, Chandigarh. C.albicans -ATCC90028, C. parapsilosis ATCC22019, C. tropicalis ATCC 750, $C$. krusei ATCC 6258.

\section{Statistical Analysis}

Data analysis done by using SPSS software version 20. Descriptive statistics such as mean, standard deviation (SD), proportions and graphs were used to describe the data. Differences between proportions were analyzed using chi square test or by Fisher's exact test.

Ethical Clearance was obtained from institutional ethical committee.

\section{Results and Discussion}

During the study period, all the clinical specimens showing Candida isolation in two consecutive samples were included in the study, thus a total number of 150 Candida isolated from various clinical specimens were subjected to Speciation and antifungal susceptibility testing. The prevalence of Candida species were studied in relation to age, sex, site of isolation, underlying risk factors, different species of Candida isolated and their antifungal susceptibility pattern. In our study, the highest incidence was seen in the age group above 60 years $(29.3 \%)$, and the least incidence was seen in the $0-10$ years of age group (6\%). Candida isolates were present in $94(62.6 \%)$ males and 56 (37.3\%) females. Male : Female ratio is $2: 1$ (Table 1).

In the study, prolonged use of antibiotics was the major risk factor constituting 41(27.3\%) followed by Biomedical devices $32(21.3 \%)$, Medical causes 21(14\%), which include - pleural effusion, bronchopneumonia and tuberculosis. Diabetes mellitus 17(11.3\%), Trauma 14(9.3\%), Surgical causes 11(7.3\%), Pregnancy $7(4.7 \%)$, Birth asphyxia 5(3.3\%) and HIV 2(1.3\%). In all these patients with above predisposing factors, the incidence of non albicans Candida $120(80 \%)$ is more than C.albicans 30 (20\%). It is statistically not significant ( $\mathrm{P}>0.005$ ) (Table 2). Total of $90(60 \%)$ isolates were obtained from urine (candiduria in patients with risk factors) followed by respiratory samples 26 $(17.3 \%)$ (which include sputum - 17, Throat swab - 3, Tracheal aspirate - 4, Bronchial alveolar lavage - 20), Blood 16 (10.7\%), High vaginal swabs (vulvovaginitis) 14 $(9.3 \%)$ and wound swabs 4 (2.7\%) respectively (Table 3 ).

In the present study nine species of Candida were characterised using standard conventional method. Candida tropicalis was the main species $86(57.33 \%)$ followed by $C$. albicans 30 (20\%). The following non-albicans species were isolated. C.dubliniensis 12 (8\%), C.krusei 7 (4.7\%), C.guilliermondii 5(3.3\%), C.kefyr 4 (2.7\%), C.lipolytica 3 (2\%), C.glabrata 2(1.3\%) and 
C.famata $1(0.6 \%)$. Higher incidence of $C$. tropicalis was found in urine $63(70 \%)$ followed by blood $10(62.5 \%)$, respiratory samples 7 (26.9\%), vaginal swab 5(35.7\%) and wound swab $1(25 \%)$. C.albicans were more frequently isolated from urine $17(18.8 \%)$ followed by respiratory samples 9(34.5\%), and Vaginal swabs 4(28.5\%), C.dubliniensis was isolated from respiratory samples 6(23\%), urine 2(2.2\%), blood 2(12.5\%), vaginal swab 2(14.2\%). C.krusei was found in urine $2(2.2 \%)$, respiratory samples $2(7.6 \%)$, vaginal swabs $2(14.2 \%)$ and $1(25 \%)$ from wound swab.

C.guilliermondii was isolated from urine 1(1.1\%), blood samples 3(18.7\%), and $1(25 \%)$ from wound swab. C.kefyr was frequently isolated from urine $2(2.2 \%)$, respiratory samples $1(3.8 \%)$, Blood 1(6.2\%). C.lipolytica was isolated from urine 2 (2.2\%), respiratory samples $1(3.8 \%)$. C.glabrata was found in urine $1(1.1 \%)$ and vaginal swab $1(7.1 \%) .1(25 \%)$ of C.famata was isolated from wound swab (Table 4).

In our study, all the isolates of C.albicans, C.dubliniensis, C.krusei, and C.guilliermondii and C.glabrata, were easily identified by chrom agar. Four strains which were identified as $C$. tropicalis by chromogenic agar were identified as one mixed growth of C. tropicalis and C. kefyr, 2 strains were identified as C.lipolytica and one as C.famata by conventional method. Among the 5 isolates of C. kefyr on chromogenic agar one strain turned to be C.lipolytica by conventional method. However, conventional method identification was taken into final consideration (Table 5). The sensitivity and specificity of CHROM agar was $100 \%$ for C. albicans, C.dubliniensis, C.krusei, C. guilliermondii, C. lipolytica, C.glabrata and C. famata. For $C$. tropicalis the sensitivity was $100 \%$ and specificity was $95.31 \%$ and for C. kefyr the sensitivity was $100 \%$ and specificity was $99.3 \%$ (Table 6).

In the present study, $98.7 \%$ of Candida species were susceptible to nystatin and only $1.3 \%$ were resistant. C.albicans showed $100 \%$ susceptibility to nystatin. Among NAC, C.lipolytica showed higher resistance (33.4\%) to Nystatin than C. tropicalis $(1.2 \%)$ respectively. The results of susceptibilities to Amphotericin B indicated that most of the tested isolates $97.3 \%$ were sensitive and only $2.7 \%$ of isolates were resistant. C.albicans showed $100 \%$ susceptibility to Amphotericin. Among NAC, C.guilliermondii, C.lipolytica and $C$. tropicalis showed $40 \%, 33.4 \%$ and $1.2 \%$ resistance to Amphotericin B respectively. In the present study, $90 \%$ of tested isolates showed susceptibility to Ketoconazole. C.albicans showed $83.3 \%$ susceptibility. Among NAC, C.krusei, C.guilliermondii, C.kefyr, C.glabrata and C.famata showed $100 \%$ susceptibility. C. tropicalis, C.dubliniensis and C.lipolytica showed $91.8 \%, 91.6 \%$ and $33.4 \%$ susceptibility respectively. Voriconazole was the next effective drug with $82 \%$ susceptibility followed by Clotrimazole $73.3 \%$, Itraconazole $72.7 \%$, and Fluconazole 69.3\% respectively. The susceptibility of C.albicans to Clotrimazole \& Itraconazole was $71.6 \%$ and $75.8 \%$ respectively.

C.albicans showed $76.6 \%$ and $63.3 \%$ susceptibility to voriconazole\& Fluconazole. Among NAC, C.krusei, C.guilliermondii, C.kefyr, C.glabrata and C.famata showed $100 \%$ susceptibility to Voriconazole. C.krusei shows innate resistance to fluconazole. C.kefyr, C.glabrata showed $100 \%$ susceptibility to fluconazole. $C$. guilliermondii showed $60 \%$ susceptibility \& only $40 \%$ of isolates were resistant. The susceptibility of C. tropicalis to Voriconazole and fluconazole was $81.3 \%$ 
and $77.9 \%$ respectively. The susceptibility of C.dubliniensis and C.lipolytica to Voriconazole was $75 \% \& 66.6 \%$ and for fluconazole was $\quad 66.6 \% \quad \& \quad 33.4 \%$ respectively (Table 7).

Fungal infections due to Candida spp., especially those that are caused by nonalbicans species, increased enormously (Colombo, 2003).

Major factors Causing Candidiasis include advances in medicine, expansion of human life span \& immunodeficiency (Filloti.et al.,2007), (Cuetara, et al.,2006). Candida species colonise the mucosal surfaces of all humans soon after birth. In the immunocompetent host several conditions predispose fungal infections like prolonged antibacterial therapy, corticosteroid use, integumentary breach as in intravenous or intra arterial catheters, surgical procedures, poor nutritional status and metabolic derangements (Chander, 2009). The extensive use of antimycotic drugs for prolonged therapeutic courses led to change in the relative prevalence of various species of Candida (Rippon JW. 1988), (Merz WG. et al., 2005).

The present study identified the specific species of Candida that causes infections among patients who attended NRI Medical College and General Hospital. The antifungal agents tested include Amphotericin B, Nystatin, Fluconazole, Clotrimazole, Voriconazole, Itraconazole, and Ketoconazole.

Candida albicans and non-albicans species are closely related but differ from each other with respect to epidemiology, virulence characters and antifungal susceptibility. All Candida species have been known to cause a similar spectrum of disease ranging from oral thrush to invasive disease, yet differences in disease severity and susceptibility to different antifungal agents have been reported (Vazquez JA.et al., 2002), (Fridkin MA. et al., 1996).

Many studies in the past decade showed the isolation of various species of Candida and increase in isolation of non albicans Candida in these situations and similar results were obtained in the present study.

In our study, it was found that candidiasis can occur at all ages and in both sexes. The youngest in our study was one week old baby while the oldest was 83 years old man and the mean age was 44.5 years. The majority of the patients were in the age group of 21-60 years. Sahni et al, (Sahni V et al., 2005) in their study, the mean age was 43.4 years. In another study (Mirdha B R et al., 1998) the age range for funguria was 175 years. The age and sex distribution of the patients in our study correlates with the observation of other researchers like (Sachin et al., 2012, Verma et al., 2003, Hajjeh et al., 2004 and Ragini et al., 2011).

Sex distribution in present study showed that males are more commonly effected than females with an incidence of $94(62.6 \%)$ and $56(37.3 \%)$ respectively in a ratio of $2: 1$ (M:F). In our study, females are more commonly affected in the age group of 2130 years 15 (26.7\%), this might be related to the fact that this is the child bearing age group when a greater hormonal variation occur. In a similar study conducted by Lata $\mathrm{R}$ patel, et al., (2012), had a male preponderance with an overall male: female ratio being $2: 1$, observed that male sex is a risk factor for developing candidemia. Ragini et al., 2011 also reported male preponderance, with an overall male: female ratio being 1: 0.81. Singh SC. et al., 2004 PGIMER Chandigarh observed that male sex is a risk factor for developing 
fungaemia. Yashawanth, et al., 2013 and Shivaprakasha, et al., 2007, also reported male preponderance.

Candidiasis occurs in the presence of risk factors (Table - 2) prolonged Medication for $>7$ days was the leading risk factors in this study. In this group $33(27.5 \%)$ isolates were NAC. The antibiotics that were used were cephalosporins, carbapenems and gentamicin. Chakrabarthi, et al., 2005, observed that patients with antibiotics $>7$ days, patients on immunosuppressants/ steroids, patients receiving 3 or more antibiotics, had infections with Candida species. Administration of broad-spectrum antibiotics suppresses the endogenous micro flora, permitting fungal overgrowth and any impairment of mucosal immunity is a potential threat for dissemination of Candida (Chakrabarthi, et al., 1999).

Biomedical devices was the second commonest risk factor noted 27 (22.5\%) with NAC. Devices such as stents, shunts, prosthesis, implants, endotracheal tubes, pacemakers, and various types of catheters, to name a few, have all been shown to support colonisation and biofilm formation by Candida (Kojic, et al.,2004) Biofilm production found to be of more significance to NAC than Candida albicans. Catheter related infections are the major cause of morbidity and mortality among hospitalised patients and catheter microbial biofilms are associated with $90 \%$ of these infections (Sardi, et al., 2013), Medical causes were the third commonest risk factor in our study. 21 (14\%) which include pleural effusion, bronchopneumonia and tuberculosis. The findings correlate with the study conducted by Jha, et al., 2006).

In the present study, Diabetes mellitus was the fourth most commonest risk factor. In this group $13(10.8 \%)$ were NAC. Diabetes mellitus decreases the chemotactic factors and impairs phagocytosis hence such patients are prone to infections by Candida species (Singhi, et al., 2004).

Trauma was the fifth commonest predisposing factor. In this group, 12(10\%) were NAC. Trauma patients usually have prolonged ICU stay and therefore are more prone to the hospital-acquired infections (HAIs).

Candida is becoming a very important pathogen among critically ill hospitalised patients. Surgical causes were the sixth most common predisposing factor in our study. In this group $9(7.5 \%)$ were NAC. The widespread use of invasive monitoring and therapeutic equipment in critically ill surgical patients increases the risk of fungal colonisation and infection.

In the present study, pregnancy was the seventh most common predisposing factor. The increased prevalence of genital candidiasis in pregnancy is due to the increase in the glycogen content of the vagina and thus increasing the colonization of candida. Occurrence of candidial vulvovaginitis in pregnant women causes risk of transmission to newborn infants (Narain, et al., 2003).

Birth asphyxia was the eight common predisposing factor. Disrupted mucosal barrier promotes adhesion of yeasts to the underlying epithelium (Oksala E. 1990). At the same time birth asphyxia may interfere with normal salivary flow which is integral to the maintenance of normal micro flora in mouth. Disturbed micro flora and mucosal breaks provide opportunities for fungal growth in the oral cavity (Piyush Gupt. MMA et al., 1996).

The present study showed that in patients 
who were HIV positive, NAC 2(1.6\%) were isolated. The reason for increased Candidiasis in HIV positive individuals is due to the decrease in CD4 T lymphocytes and hence a decrease in the amounts of IL-2, IFN-gamma and other lymphokines which cause major damage to the cell mediated immunity. Humoral immunity is also affected. The data of this study showed that even in different risk factors groups, it was the NAC that were isolated more frequently (Table-2).The commonest being $C$. tropicalis. In the present study, Candida species was isolated from various clinical samples and the highest was from urine in patients with risk factors $90(60 \%)$ followed by respiratory samples $26(17.3 \%)$, Blood 16(10.7\%), High vaginal swabs $14(9.3 \%)$ and wound swabs $4(2.7 \%)$.

In our study, maximum numbers of Candida species were isolated from urine samples. Candida spp. are reported as seventh most common nosocomial pathogen in hospital settings causing $25 \%$ of all the urinary tract infections in some of previous studies. Roy R.C.et al., 2013, Lata R Patel et al., 2012, Pfaller, et al., 1996, Almeida, A.A et al., 2013 had also reported most of Candida spp. from urine samples in there study $(62 \%)$.

In this study, we observed that Non-albicans Candida species had predominance over C.albicans. Among the Non-albicans Candida species, C. tropicalis showed higher prevalence followed by C.dubliniensis, C.krusei, C.guilliermondii, C.kefyr, C.lipolytica, C.glabrata, C. famata, which is consistent with the published reports from different parts of the world (Bandi et al., 2014, Tajashree et al., 2014,Geeta S.H., 2014, Lata R Patel. et al., 2012, Saroj Golia.et al., 2013, Agarwal, et al., 2011). C. tropicalis was the most common isolate, followed by C.albicans. A relatively greater proportion of $C$. tropicalis isolates in our study is concordant with other studies from India (Bandi et al., 2014, Ragini et al., 2011. This is represented in the (Figure- 1).

Furthermore, Invasive candida infection was mostly caused by Non-albicans Candida. Non-albicans Candida was alone more prevalent in paediatric and older patients groups than in patients of young age group. The findings are also in agreement with the studies conducted by Chakrabarti A.et al.,1996 and 2002, Agarwal J. et al. 2004,Singhi SC.et al.,2004.In some of the other studies the percentage of C.albicans was higher than NAC which is in contrast to the present study. St.Germian, et al.,2001, Amar, et al.,2013, Basu, et al., 2003,Vijaya, et al.,2011 and Saroj Golia, et al., 2013.

For differentiation between different species of candida conventionally Germ tube test, chlamydospore formation, sugar fermentation and assimilation tests are being used which are laborious and time consuming and may take 72 hrs to 2 weeks. Chrom agar helps in rapid identification of most of the species of candida. It can serve a primary isolation and differentiation medium for clinical specimens likely to contain yeast and also an adjunctive differential medium for identification of yeasts isolated on other media. A major advantage of CHROM Agar (HICROME Agar, HI MEDIA, Mumbai) is the ability to detect mixed cultures of yeast in clinical specimens (Baradkar, et al., 2010).

The Varying sensitivities and specificities have been reported by several authors for identification of Candida species. Sensitivities ranged from $66.7 \%$ to $100 \%$, specificity from 78.8 to $100 \%$ in a study done by Amar, et al., 2013, Syamala, et al., 2012. The present study showed sensitivity $100 \%$ and specificity $95.31 \%$ which is in 
between the rates reported by Amar, et al., 2013, Willinger, et al., 1999, Yucesoy, et al., 2003, Peng, et al2007and Shyamala, et al., 2012. We found it difficult to objectively identify colony characters like pink to lavender and steel blue or met allic blue colour. Other test like CMA and SAT need to be done in case of ambiguity.

Similarly varying sensitivities and specificities have been reported by several authors for identification of C.albicans. Shyamala, et al., 2012 who used Hicrome agar reported a good sensitivity $(97.05 \%)$ and specificity (98.07\%), Bharadkar, et al., 2010 reported a sensitivity of $96.55 \%$ and specificity of $96.42 \%$. Willinger, et al., 1999 reported $98.8 \%$ and $100 \%$, Peng, et al., 2007, 100\% and 94.6\% and Yucesoy, et al., 2003 reported $99.4 \%$ and $100 \%$ of sensitivity and specificity. In our study we found $100 \%$ sensitivity and specificity for C.albicans which is in agreement with Amar C S. et al., 2013 and Yucesoy M. et al., 2003.

The present study had 12 isolates of C.dubliniensis which was easily identified by their dark green colouration. Thus for C.dubliniensis sensitivity and specificity on Hicrome agar was found to be $100 \%$. In a study conducted by Baradkar et al., 2010 showed low sensitivity (60\%) and specificity $(96.55 \%)$.

Jabra-Rizk, et al., 2005 and Faller, et al., 1996 suggested the same colour for C.dubliniensis. The present study shows $100 \%$ sensitivity and specificity. The isolate was easily identified by their rough, fuzzy, spreading large pink colonies on CHROM agar, which is in concordance with Yucesoy et al., 2003 and Amar et al., 2013 revealed that all C.krusei isolates produced rough, fuzzy spreading big pink colonies on CHROM agar. Yucesoy et al.,2003 opines that although there are many yeast species giving the same colour, the morphology of the colonies of C.krusei is distinctly different (fuzzy, rough, large, pink).

In our study C.guilliermondii and C.glabrata was easily identified by their colour, pink to lavender and dark violet colour for C.glabrata. Hence, the sensitivity and specificity of both species was found to be $100 \%$.

Rapid identification of $C$. glabrata has a special importance because $C$. glabrata is less sensitive than other species to ketoconazole and fluconazole (Abi-Said D.et al., 1997, Khan ZU.et al., 2004), Baradkar VP et al., 2010 reported, a sensitivity of $90.90 \%$ and specificity of $88.23 \%$ were reported.

Willinger et al., 1999 reported 98\% sensitivity and $95.7 \%$ specificity for $C$. glabrata on chrom agar. Peng et al., 2007 reported sensitivity and specificity values of chrome agar for $C$. glabrata as 90.2 and 95.4\% respectively. C. kefyr, C. lusitaniae, C. guilliermondii produced similar colonies as described by many authors (Freydiere AM.,1996) (Koehler AP. et al.,1999). In our study sensitivity and specificity of C.kefyr was found to be $100 \%$ and $99.3 \%$. These strains can be easily differentiated from $\mathrm{C}$. glabrata as it doesn't produce even pseudo hyphae on cornmeal agar. Thus the combination of cornmeal agar and chrome agar can be used for early identification of C. glabrata.

In our study, chromogenic medium and morphology on CMA did not enable the differentiation of C.famata, C.lipolytica. However these isolates could be clustered as those providing white to pink colonies on Chrom agar and providing only yeast cells (yeast cells without pseudohyphae) on CMA. 
In the present study these two species can be easily identified by sugar fermentation and sugar assimilation test. The present findings are in concordance with Sanjeev kumar et al., 2013, who opined that all such isolates could be successfully identified only through automated systems i.e. the V2C system. Thus Vitek 2 ID could be an additional help in those situations where CHROM agar could not give identification (LO, et al., 2001).

However V2C is expensive and its use in most of the hospitals in developing countries like India cannot be justified. CHROM agar was certainly the more efficient method over Vitek 2 for identification of most commonly isolated species from our hospital. However there were certain limitations in our study such as very few isolates of $\mathrm{C}$. famata and $C$. lipolytica for comparison with other authors.

The invitro susceptibility testing of antifungal agents is becoming increasingly important because of the introduction of new antifungal agents and the recovery of clinical isolates that exhibit inherent or developed resistance to Amphotericin B, Nystatin and the Azole group of drugs during chemotherapy.

In the present study we performed disc diffusion method for antifungal susceptibility testing of candida isolates. In our study, $27.3 \%$ showed resistance to Itraconazole, $26.7 \%$ showed resistance to clotrimazole, $26 \%$ showed resistance to Fluconazole, $18 \%$ showed resistance to voriconazole, $10 \%$ showed resistance to ketoconazole, $2.7 \%$ showed resistance to Amphotericin B, $1.3 \%$ showed resistance to Nystatin. The comparative study of fluconazole resistance is shown in figure -
2. In the present study, isolation of NAC is more than C.albicans. Identification of candida species is important as non-albicans Candida are more resistant to azoles compared to C.albicans.

All the isolates of candida were susceptible to Amphotericin B and Nystatin except C.guilliermondii and C.lipolytica which showed $60 \%$ and $66.6 \%$ susceptiblility. Next to Amphotericin B \& Nystatin, NAC were susceptible to ketoconazole. Only C.lipolytica showed higher resistance to Ketoconazole $(66.6 \%)$ in our study. Jayalakshmi et al.,2014 from South India reported similar finding.

In this study, all the species of candida except C.kefyr were susceptible to Amphotericin B \& Nystatin. Ketoconazole showed $83.8 \%$ susceptibility followed by Itraconazole and Clotrimazole $75.23 \%$ and $71.42 \%$.

Fluconazole is $69.3 \%$ susceptible, of which $22 \%$ strains of C. tropicalis showed resistance against Fluconazole and $77.9 \%$ were susceptible. C.famata showed complete resistance to Fluconazole, Clotrimazole, Itraconazole whereas C.dubliniensis \& C.guilliermondii showed $33.4 \%$ and $40 \%$ resistance to Fluconazole.

C.glabrata showed $100 \%$ susceptibility to Fluconazole in our study which is in contrast to Farooqi et al.,2013 showed higher resistance to fluconazole by C.glabrata.Itraconazole and Clotrimazole showed highest resistance $27.3 \%$ and $26.7 \%$ respectively among NAC. Our study is in concordance with the study done by Geeta $\mathrm{S}$ et al.,2014, and Jayalakshmi et al.,2014. 
Table.1 Distribution of Patients according to age and sex in culture positive cases

\begin{tabular}{|l|c|c|c|}
\hline \multirow{2}{*}{ AGE } & \multicolumn{2}{|c|}{ Culture positive cases } & \multirow{2}{*}{$\begin{array}{c}\text { Total No. of } \\
\text { Cases }\end{array}$} \\
\cline { 2 - 3 } & Males & Females & \\
\cline { 2 - 3 } $0-10$ & $5(5.3 \%)$ & $4(7.1 \%)$ & $9(6 \%)$ \\
\hline $11-20$ & $3(3.1 \%)$ & $8(14.2 \%)$ & $11(7.3 \%)$ \\
\hline $21-30$ & $11(11.7 \%)$ & $15(26.7 \%)$ & $26(17.3 \%)$ \\
\hline $31-40$ & $9(9.5 \%)$ & $9(16.0 \%)$ & $18(12 \%)$ \\
\hline $41-50$ & $18(19.1 \%)$ & $5(8.9 \%)$ & $23(15.3 \%)$ \\
\hline $51-60$ & $17(18.0 \%)$ & $2(3.5 \%)$ & $19(12.7 \%)$ \\
\hline$>60$ & $31(32.9 \%)$ & $13(23.2 \%)$ & $44(29.3 \%)$ \\
\hline TOTAL & $94(62.6 \%)$ & $56(37.3 \%)$ & $150(100 \%)$ \\
\hline Mean age $: 44.5$ years & \multicolumn{2}{|c}{ SD -20.4} \\
\hline
\end{tabular}

Table.2 Candida species among various predisposing factors.

\begin{tabular}{|l|c|c|c|}
\hline \multicolumn{1}{|c|}{ Predisposing factors } & $\begin{array}{c}\text { C.albicans } \\
(\%)\end{array}$ & $\begin{array}{c}\text { Non-albicans } \\
\text { candida (\%) }\end{array}$ & Total \\
\hline Prolonged Medication & $8(26.6)$ & $33(27.5)$ & $41(27.3 \%)$ \\
\hline Biomedical devices & $5(16.6)$ & $27(22.5)$ & $32(21.3 \%)$ \\
\hline Medical causes & $6(20)$ & $15(12.5)$ & $21(14 \%)$ \\
\hline Diabetes mellitus & $4(13.3)$ & $13(10.8)$ & $17(11.3 \%)$ \\
\hline Trauma & $2(6.6)$ & $12(10)$ & $14(9.3 \%)$ \\
\hline Surgical causes & $2(6.6)$ & $9(7.5)$ & $11(7.3 \%)$ \\
\hline Pregnancy & $3(10)$ & $4(3.3)$ & $7(4.7 \%)$ \\
\hline Birth asphyxia & 0 & $5(4.1)$ & $5(3.3 \%)$ \\
\hline H I V & 0 & $2(1.6)$ & $2(1.3 \%)$ \\
\hline Total & $30(20)$ & $120(80)$ & $150(100 \%)$ \\
\hline
\end{tabular}


Table.3 Distribution of Candida isolates in clinical specimens.

\begin{tabular}{|l|c|c|}
\hline \multicolumn{1}{|c|}{ Clinical Specimens } & \multicolumn{1}{c|}{$\begin{array}{c}\text { Total No. of } \\
\text { Isolates }\end{array}$} & Percentages \\
\hline Urine & 90 & 60 \\
\hline Respiratory samples & 26 & 17.3 \\
\hline Blood & 16 & 10.7 \\
\hline Vaginal swab & 14 & 9.3 \\
\hline Wound swab & 04 & 2.7 \\
\hline Total & 150 & 100 \\
\hline
\end{tabular}

Table.4 Distribution of different species of Candida among various clinical specimens by conventional method (CMA and SAT)

\begin{tabular}{|l|c|c|c|c|c|c|}
\hline \multicolumn{1}{|c|}{ Species } & $\begin{array}{c}\text { From Urine } \\
\text { (candiduria in } \\
\text { patients with } \\
\text { risk factors) } \\
(\boldsymbol{\%})\end{array}$ & $\begin{array}{c}\text { Respiratory } \\
\text { samples } \\
(\boldsymbol{\%})\end{array}$ & $\begin{array}{c}\text { From } \\
\text { Blood } \\
(\boldsymbol{\%})\end{array}$ & $\begin{array}{c}\text { Vaginal } \\
\text { swab } \\
\mathbf{( \% )}\end{array}$ & $\begin{array}{c}\text { Wound } \\
\text { Swab } \\
(\boldsymbol{\%})\end{array}$ & $\begin{array}{c}\text { Total } \\
\text { No. of } \\
\text { isolates } \\
(\boldsymbol{\%})\end{array}$ \\
\hline C. tropicalis & $63(70)$ & $7(26.9)$ & $10(62.5)$ & $5(35.7)$ & $1(25)$ & $86(57.3)$ \\
\hline C.albicans & $17(18.8)$ & $9(34.6)$ & 0 & $4(28.5)$ & 0 & $30(20.0)$ \\
\hline C.dubliniensis & $2(2.2)$ & $6(23)$ & $2(12.5)$ & $2(14.2)$ & 0 & $12(8.0)$ \\
\hline C.krusei & $2(2.2)$ & $2(7.6)$ & 0 & $2(14.2)$ & $1(25)$ & $7(4.7)$ \\
\hline C.guilliermondii & $1(1.1)$ & 0 & $3(18.7)$ & 0 & $1(25)$ & $5(3.3)$ \\
\hline C.kefyr & $2(2.2)$ & $1(3.8)$ & $1(6.2)$ & 0 & 0 & $4(2.7)$ \\
\hline C.lipolytica & $2(2.2)$ & $1(3.8)$ & 0 & 0 & 0 & $3(2.0)$ \\
\hline C.glabrata & $1(1.1)$ & 0 & 0 & $1(7.1)$ & 0 & $2(1.3)$ \\
\hline C.famata & 0 & 0 & 0 & 0 & $1(25)$ & $1(0.66)$ \\
\hline Total & $90(60)$ & $26(17.3)$ & $16(10.7)$ & $14(9.3)$ & $4(2.7)$ & $150(100)$ \\
\hline Chi square test : 294.12 & & P valve $<0.05$, Significant. & \\
\hline
\end{tabular}


Table.5 Identification of species by CHROM agar \& Conventional method

\begin{tabular}{|c|c|c|}
\hline Species & CHROM agar & $\begin{array}{c}\text { Conventional method } \\
\text { (CMA \& SAT) }\end{array}$ \\
\hline C. tropicalis & $89(59.3 \%)$ & $86(57.3 \%)$ \\
\hline C.albicans & $30(20 \%)$ & $30(20 \%)$ \\
\hline C.dubliniensis & $12(8 \%)$ & $12(8 \%)$ \\
\hline C.krusei & $07(4.7 \%)$ & $07 \quad(4.7 \%)$ \\
\hline C.guilliermondii & $05(3.3 \%)$ & $05(3.3 \%)$ \\
\hline C.kefyr & $05(3.3 \%)$ & $04(2.7 \%)$ \\
\hline C.lipolytica & 0 & $03(2.0 \%)$ \\
\hline C.glabrata & $02(1.3 \%)$ & $02(1.3 \%)$ \\
\hline C.famata & 0 & $01 \quad(0.66 \%)$ \\
\hline Total & $150(100 \%)$ & $150(100 \%)$ \\
\hline
\end{tabular}

Table.6 Sensitivity and specificity of CHROM agar for identification of various Candida species

\begin{tabular}{|l|c|c|c|c|}
\hline \multicolumn{1}{|c|}{ Species } & $\begin{array}{c}\text { Total Candida } \\
\text { species identified } \\
\text { using CHROM } \\
\text { agar }\end{array}$ & $\begin{array}{c}\text { No. of Candida } \\
\text { species identified by } \\
\text { conventional } \\
\text { method (CMA \& } \\
\text { SAT) }\end{array}$ & $\begin{array}{c}\text { Sensitivity } \\
\text { of } \\
\text { CHROM } \\
\text { agar }\end{array}$ & $\begin{array}{c}\text { Specificity of } \\
\text { CHROM } \\
\text { agar }\end{array}$ \\
\hline C. tropicalis & $89(59.3 \%)$ & $86(57.3 \%)$ & $100 \%$ & $95.31 \%$ \\
\hline C.albicans & $30(20 \%)$ & $30(20 \%)$ & $100 \%$ & $100 \%$ \\
\hline C.dubliniensis & $12(8 \%)$ & $12(8 \%)$ & $100 \%$ & $100 \%$ \\
\hline C.krusei & $07(4.7 \%)$ & $07(4.7 \%)$ & $100 \%$ & $100 \%$ \\
\hline C.guilliermondii & $05(3.3 \%)$ & $05(3.3 \%)$ & $100 \%$ & $100 \%$ \\
\hline C. kefyr & $05(3.3 \%)$ & $04(2.7 \%)$ & $100 \%$ & $99.3 \%$ \\
\hline C.lipolytica & 0 & $03(2.0 \%)$ & $0 \%$ & $100 \%$ \\
\hline C.glabrata & $02(1.3 \%)$ & $02(1.3 \%)$ & $100 \%$ & $100 \%$ \\
\hline C.famata & 0 & $01(0.7 \%)$ & $0 \%$ & $100 \%$ \\
\hline
\end{tabular}


Table.7 Antifungal susceptibility of Candida species

\begin{tabular}{|c|c|c|c|c|c|c|c|c|c|c|c|c|c|c|}
\hline \multirow{2}{*}{ Species } & \multicolumn{2}{|c|}{$\begin{array}{c}\text { FLU } \\
(10 \mu g)\end{array}$} & \multicolumn{2}{|c|}{$\begin{array}{c}\text { CLO } \\
(10 \mu g)\end{array}$} & \multicolumn{2}{|c|}{$\begin{array}{l}\text { VOR } \\
(1 \mu \mathrm{g})\end{array}$} & \multicolumn{2}{|c|}{$\begin{array}{c}\text { ITR } \\
(10 \mu \mathrm{g})\end{array}$} & \multicolumn{2}{|c|}{$\begin{array}{c}\text { KETO } \\
(1 \mu \mathrm{g})\end{array}$} & \multicolumn{2}{|c|}{$\begin{array}{c}\text { NYS } \\
(100 \mathrm{U})\end{array}$} & \multicolumn{2}{|c|}{$\begin{array}{c}\text { AMB } \\
\text { (100U) }\end{array}$} \\
\hline & $\mathbf{S}$ & $\mathbf{R}$ & $\mathbf{S}$ & $\mathbf{R}$ & $\mathbf{S}$ & $\mathbf{R}$ & $\mathbf{S}$ & $\mathbf{R}$ & $\mathbf{S}$ & $\mathbf{R}$ & $\mathbf{S}$ & $\mathbf{R}$ & $\mathbf{S}$ & $\mathbf{R}$ \\
\hline $\begin{array}{c}C . \\
\text { tropicalis } \\
(\mathrm{n}=86)\end{array}$ & $\begin{array}{c}67 \\
77.9 \\
\%\end{array}$ & $\begin{array}{c}19 \\
22 \%\end{array}$ & $\begin{array}{c}59 \\
68.6 \\
\%\end{array}$ & $\begin{array}{c}27 \\
31.3 \\
\%\end{array}$ & $\begin{array}{c}70 \\
81.3 \\
\%\end{array}$ & $\begin{array}{c}16 \\
18.6 \\
\%\end{array}$ & $\begin{array}{c}70 \\
81.3 \\
\%\end{array}$ & $\begin{array}{c}16 \\
18.6 \\
\%\end{array}$ & $\begin{array}{c}79 \\
91.8 \\
\%\end{array}$ & $\begin{array}{c}7 \\
8.1 \\
\%\end{array}$ & $\begin{array}{c}85 \\
98.8 \\
\%\end{array}$ & $\begin{array}{c}1 \\
1.2 \\
\%\end{array}$ & $\begin{array}{c}85 \\
98.8 \\
\%\end{array}$ & $\begin{array}{c}1 \\
1.2 \\
\%\end{array}$ \\
\hline $\begin{array}{l}\text { C.albicans } \\
\qquad(\mathrm{n}=30)\end{array}$ & $\begin{array}{c}19 \\
63.3 \\
\%\end{array}$ & $\begin{array}{c}11 \\
36.6 \\
\%\end{array}$ & $\begin{array}{c}24 \\
80 \%\end{array}$ & $\begin{array}{c}6 \\
20 \%\end{array}$ & $\begin{array}{c}23 \\
76.6 \\
\% \\
\end{array}$ & $\begin{array}{c}7 \\
23.4 \\
\%\end{array}$ & $\begin{array}{c}18 \\
60 \%\end{array}$ & $\begin{array}{c}12 \\
40 \%\end{array}$ & $\begin{array}{c}25 \\
83.3 \\
\%\end{array}$ & $\begin{array}{c}5 \\
16 . \\
7 \%\end{array}$ & $\begin{array}{c}30 \\
100 \\
\%\end{array}$ & 0 & $\begin{array}{c}30 \\
100 \\
\%\end{array}$ & 0 \\
\hline $\begin{array}{c}\text { C.dublinie } \\
n s i s \\
(\mathrm{n}=12)\end{array}$ & $\begin{array}{c}8 \\
66.6 \\
\%\end{array}$ & $\begin{array}{c}4 \\
33.4 \\
\%\end{array}$ & $\begin{array}{c}10 \\
83.3 \\
\%\end{array}$ & $\begin{array}{c}2 \\
16.7 \\
\%\end{array}$ & $\begin{array}{c}9 \\
75 \\
\%\end{array}$ & $\begin{array}{c}3 \\
25 \%\end{array}$ & $\begin{array}{c}7 \\
58.3 \\
\%\end{array}$ & $\begin{array}{c}5 \\
41.7 \\
\%\end{array}$ & $\begin{array}{c}11 \\
91.6 \\
\%\end{array}$ & $\begin{array}{c}1 \\
8.4 \\
\%\end{array}$ & $\begin{array}{c}12 \\
100 \\
\%\end{array}$ & 0 & $\begin{array}{c}12 \\
100 \\
\%\end{array}$ & 0 \\
\hline $\begin{array}{c}\text { C.krusei } \\
(\mathrm{n}=7)\end{array}$ & 0 & 0 & $\begin{array}{c}5 \\
71.4 \\
\%\end{array}$ & $\begin{array}{c}2 \\
28.4 \\
\%\end{array}$ & $\begin{array}{c}7 \\
100 \\
\%\end{array}$ & 0 & $\begin{array}{c}4 \\
57.1 \\
\%\end{array}$ & $\begin{array}{c}3 \\
42.9 \\
\%\end{array}$ & $\begin{array}{c}7 \\
100 \\
\%\end{array}$ & 0 & $\begin{array}{c}7 \\
100 \\
\%\end{array}$ & 0 & $\begin{array}{c}7 \\
100 \\
\%\end{array}$ & 0 \\
\hline $\begin{array}{c}\text { C.guillierm } \\
\text { ondii } \\
(\mathrm{n}=5)\end{array}$ & $\begin{array}{c}3 \\
60 \%\end{array}$ & $\begin{array}{c}2 \\
40 \%\end{array}$ & $\begin{array}{c}4 \\
80 \%\end{array}$ & $\begin{array}{c}1 \\
20 \%\end{array}$ & $\begin{array}{c}5 \\
100 \\
\%\end{array}$ & 0 & $\begin{array}{c}5 \\
100 \\
\%\end{array}$ & 0 & $\begin{array}{c}5 \\
100 \\
\%\end{array}$ & 0 & $\begin{array}{c}5 \\
100 \\
\%\end{array}$ & 0 & $\begin{array}{c}3 \\
60 \%\end{array}$ & $\begin{array}{c}2 \\
40 \\
\%\end{array}$ \\
\hline $\begin{array}{c}\text { C.kefyr } \\
(\mathrm{n}=4)\end{array}$ & $\begin{array}{c}4 \\
100 \\
\%\end{array}$ & 0 & $\begin{array}{c}4 \\
100 \\
\%\end{array}$ & 0 & $\begin{array}{c}4 \\
100 \\
\%\end{array}$ & 0 & $\begin{array}{c}3 \\
75 \%\end{array}$ & $\begin{array}{c}1 \\
25 \%\end{array}$ & $\begin{array}{c}4 \\
100 \\
\%\end{array}$ & 0 & $\begin{array}{c}4 \\
100 \\
\%\end{array}$ & 0 & $\begin{array}{c}4 \\
100 \\
\%\end{array}$ & 0 \\
\hline $\begin{array}{c}\text { C.lipolytic } \\
a(\mathrm{n}=3)\end{array}$ & $\begin{array}{c}1 \\
33.4 \\
\%\end{array}$ & $\begin{array}{c}2 \\
66.6 \\
\%\end{array}$ & $\begin{array}{c}2 \\
66.6 \\
\%\end{array}$ & $\begin{array}{c}1 \\
33.4 \\
\%\end{array}$ & $\begin{array}{c}2 \\
66.6 \\
\%\end{array}$ & $\begin{array}{c}1 \\
33.4 \\
\%\end{array}$ & $\begin{array}{c}1 \\
33.4 \\
\%\end{array}$ & $\begin{array}{c}2 \\
66.4 \\
\%\end{array}$ & $\begin{array}{c}1 \\
33.4 \\
\%\end{array}$ & $\begin{array}{c}2 \\
66 . \\
6 \%\end{array}$ & $\begin{array}{c}2 \\
66.6 \\
\%\end{array}$ & $\begin{array}{c}1 \\
33 . \\
4 \%\end{array}$ & $\begin{array}{c}2 \\
66.6 \\
\%\end{array}$ & $\begin{array}{c}1 \\
33 . \\
4 \%\end{array}$ \\
\hline $\begin{array}{l}\text { C. glabrata } \\
\qquad(\mathrm{n}=2)\end{array}$ & $\begin{array}{c}2 \\
100 \\
\%\end{array}$ & 0 & $\begin{array}{c}1 \\
50 \%\end{array}$ & $\begin{array}{c}1 \\
50 \%\end{array}$ & $\begin{array}{c}2 \\
100 \\
\%\end{array}$ & 0 & $\begin{array}{c}1 \\
50 \%\end{array}$ & $\begin{array}{c}1 \\
50 \%\end{array}$ & $\begin{array}{c}2 \\
100 \\
\%\end{array}$ & 0 & $\begin{array}{c}2 \\
100 \\
\%\end{array}$ & 0 & $\begin{array}{c}2 \\
100 \\
\%\end{array}$ & 0 \\
\hline $\begin{array}{l}\text { C.famata } \\
(\mathrm{n}=1)\end{array}$ & 0 & $\begin{array}{c}1 \\
100 \\
\%\end{array}$ & 0 & $\begin{array}{c}1 \\
100 \\
\%\end{array}$ & $\begin{array}{c}1 \\
100 \\
\%\end{array}$ & 0 & 0 & $\begin{array}{c}1 \\
100 \\
\%\end{array}$ & $\begin{array}{c}1 \\
100 \\
\%\end{array}$ & 0 & $\begin{array}{c}1 \\
100 \\
\%\end{array}$ & 0 & $\begin{array}{c}1 \\
100 \\
\%\end{array}$ & 0 \\
\hline Total & $\begin{array}{c}104 \\
69.3 \\
\%\end{array}$ & $\begin{array}{c}39 \\
26 \%\end{array}$ & $\begin{array}{c}110 \\
73.3 \\
\%\end{array}$ & $\begin{array}{c}40 \\
26.7 \\
\%\end{array}$ & $\begin{array}{c}123 \\
82 \\
\%\end{array}$ & $\begin{array}{c}27 \\
18 \%\end{array}$ & $\begin{array}{c}109 \\
72.7 \\
\%\end{array}$ & $\begin{array}{c}41 \\
27.3 \\
\%\end{array}$ & $\begin{array}{l}135 \\
90 \%\end{array}$ & $\begin{array}{l}15 \\
10 \\
\%\end{array}$ & $\begin{array}{c}148 \\
98.7 \\
\%\end{array}$ & $\begin{array}{c}2 \\
1.3 \\
\%\end{array}$ & $\begin{array}{c}146 \\
97.3 \\
\%\end{array}$ & $\begin{array}{c}4 \\
2.7 \\
\%\end{array}$ \\
\hline$\chi^{2}$ & \multicolumn{2}{|c|}{3.166} & \multicolumn{2}{|c|}{7.28} & \multicolumn{2}{|c|}{3.696} & \multicolumn{2}{|c|}{15.39} & \multicolumn{2}{|c|}{14.7} & \multicolumn{2}{|c|}{24.2} & \multicolumn{2}{|c|}{40.0} \\
\hline$P$ value & \multicolumn{2}{|c|}{$\begin{array}{l}.530, \text { Not } \\
\text { significant }\end{array}$} & \multicolumn{2}{|c|}{$\begin{array}{l}0.608, \text { not } \\
\text { significant }\end{array}$} & \multicolumn{2}{|c|}{$\begin{array}{c}0.26 \text {,not } \\
\text { significant }\end{array}$} & \multicolumn{2}{|c|}{$\begin{array}{c}0.08 \text {,not } \\
\text { significant }\end{array}$} & \multicolumn{2}{|c|}{$\begin{array}{l}0.09, \text { not } \\
\text { significant }\end{array}$} & \multicolumn{2}{|c|}{$\begin{array}{c}0.004, \text { signi } \\
\text { ficant }\end{array}$} & \multicolumn{2}{|c|}{$\begin{array}{l}0.000, \text { Signi } \\
\text { ficant }\end{array}$} \\
\hline
\end{tabular}

FLU - Fluconazole, CLO-Clotrimazole, VOR- Voriconazole, ITR-Itraconazole, KETO Ketoconazole, NYS-Nystatin, AMB - Amphotericin B. 
Fig.1 Distribution of patients according to age $\&$ sex in culture positive cases

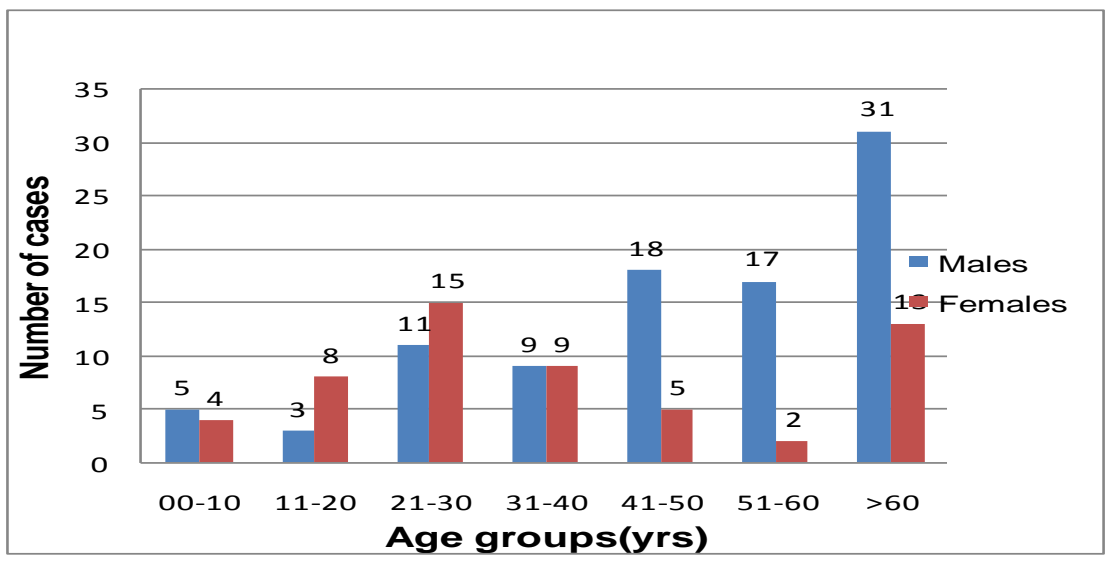

Fig.2 Candida species among various predisposing factors.

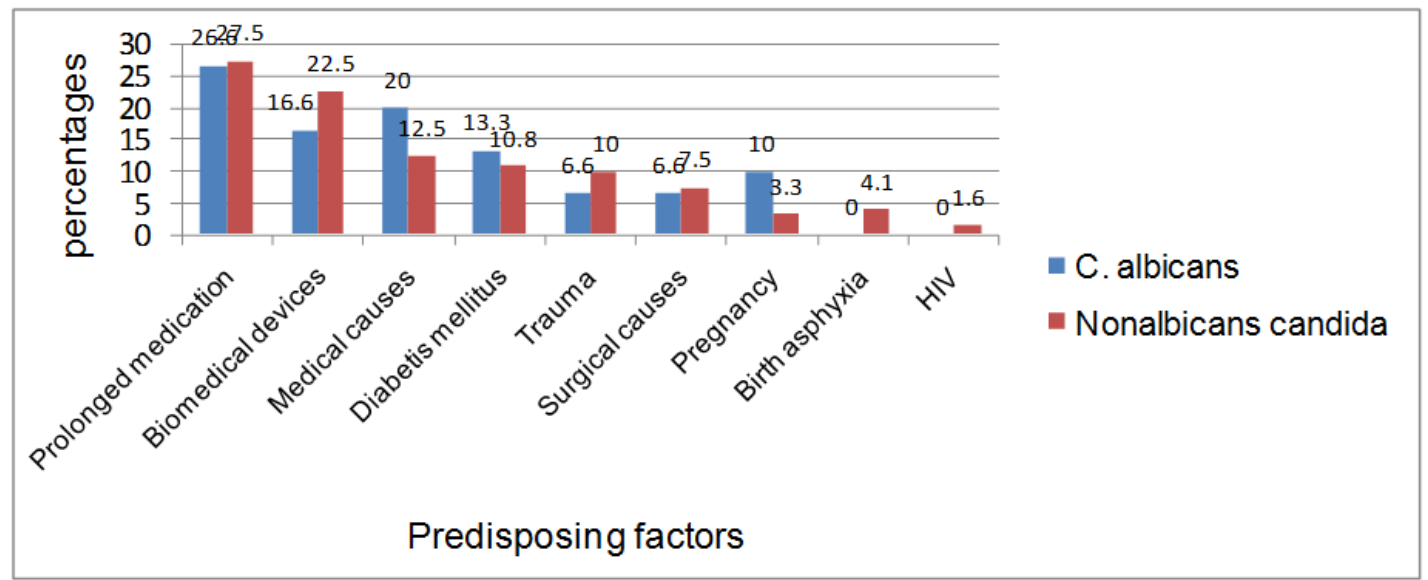

Fig.3 Distribution of Candida isolates in clinical specimens

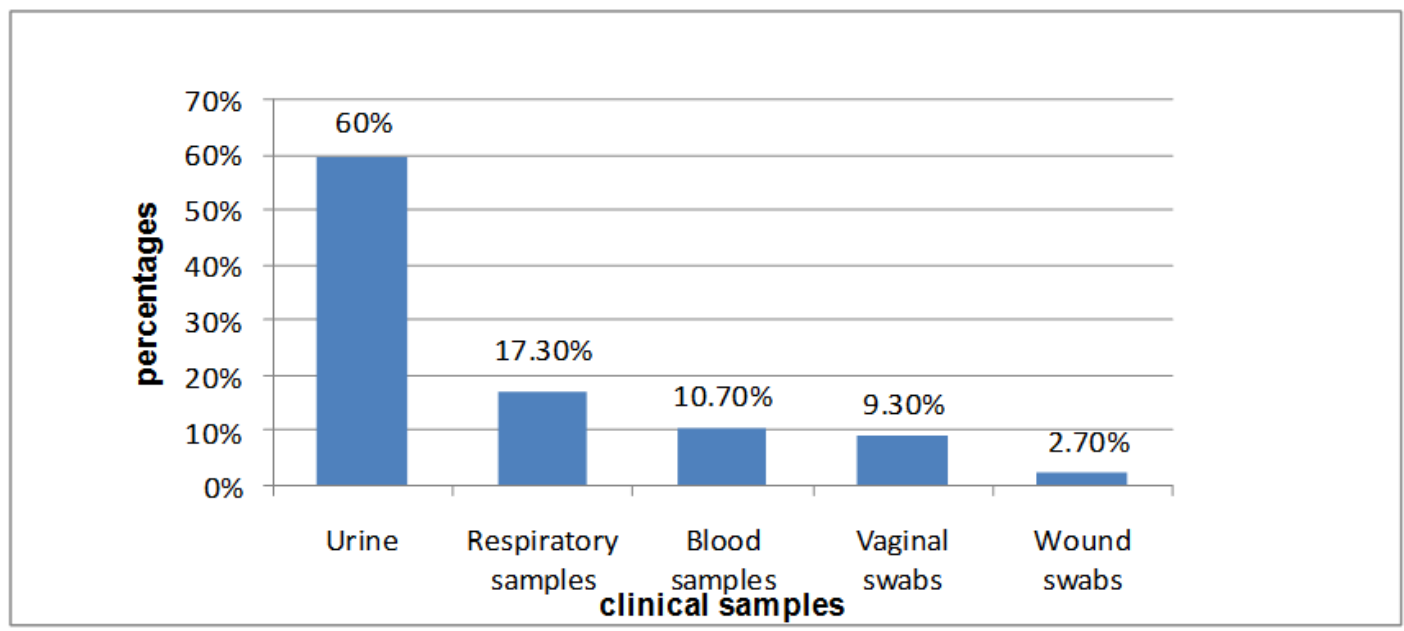


Fig.4 Distribution of different species of Candida among various clinical specimens by conventional methods (CMA \& SAT)

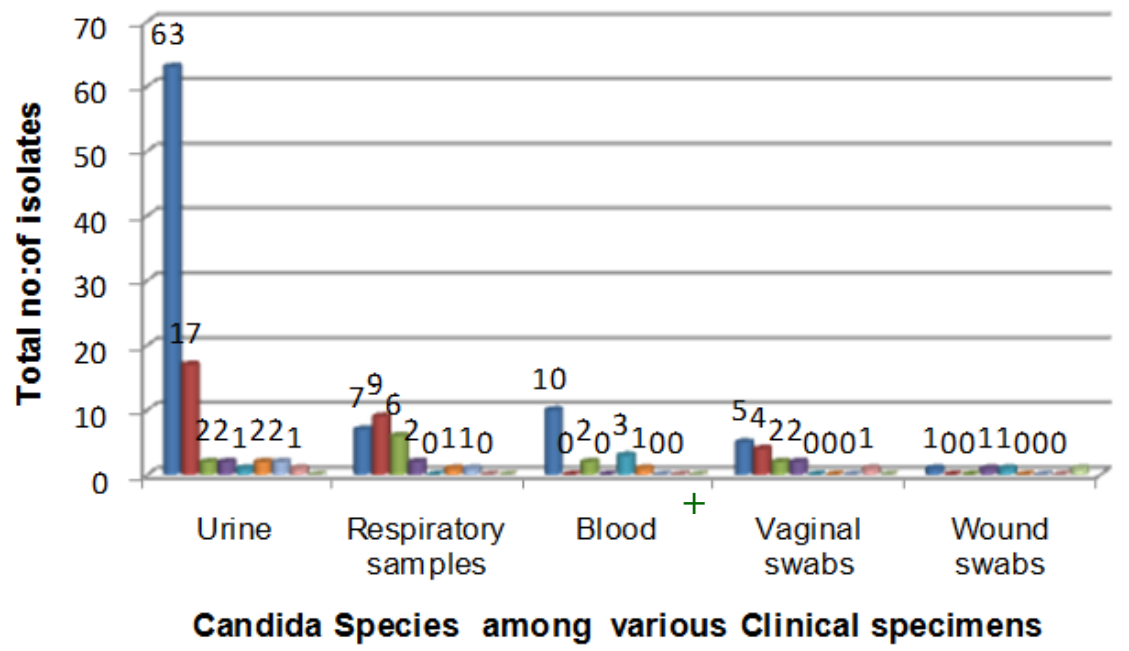

C.tropicalis

C.albicans

C.dubliniensis

C.Krusei

= C.guilliermondii

- C.kefyr

C.lipolytica

- C.glabrata

C.famata

Fig.5 Identification of species by CHROM agar \& Conventional method

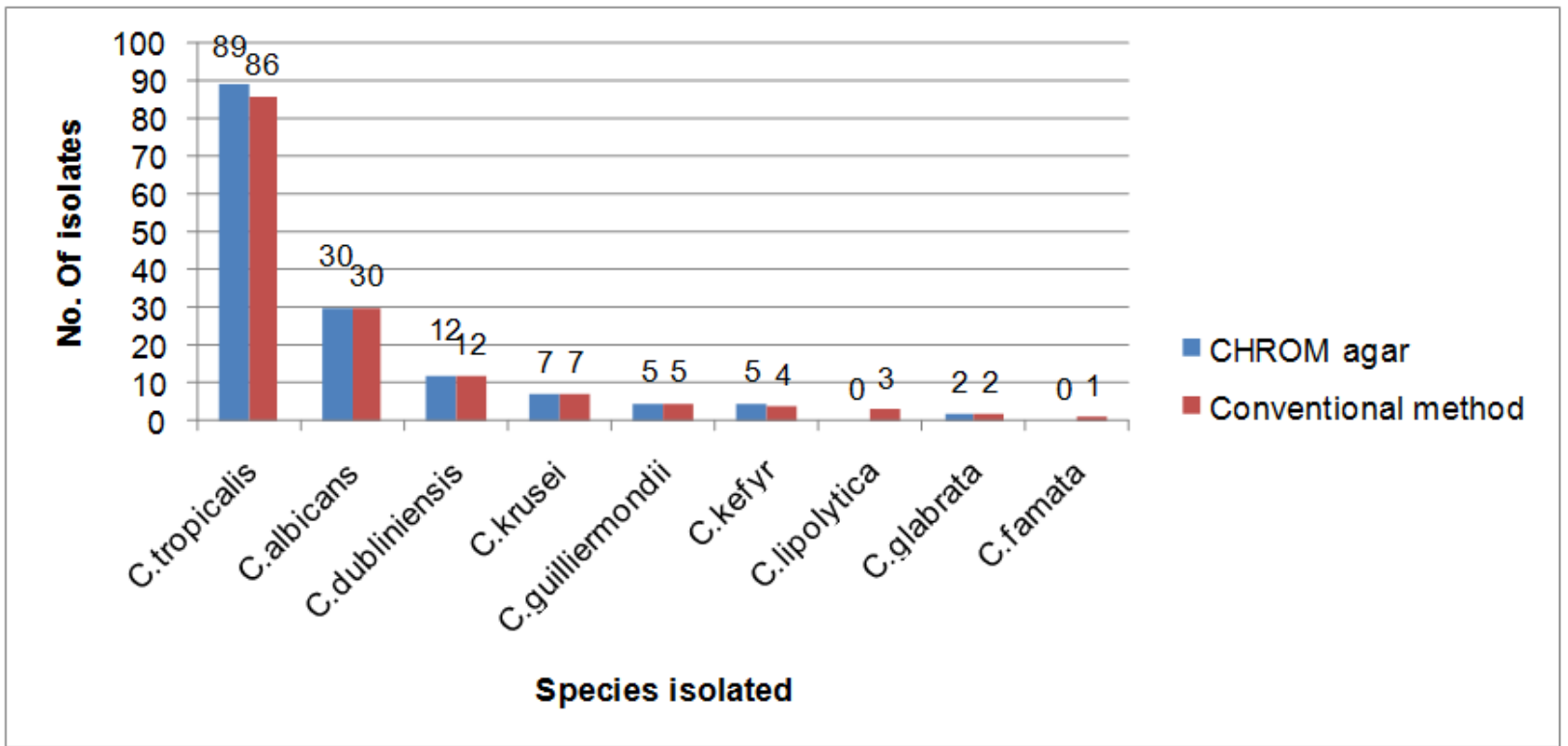


Fig.6 Antifungal susceptibility pattern of Candida species

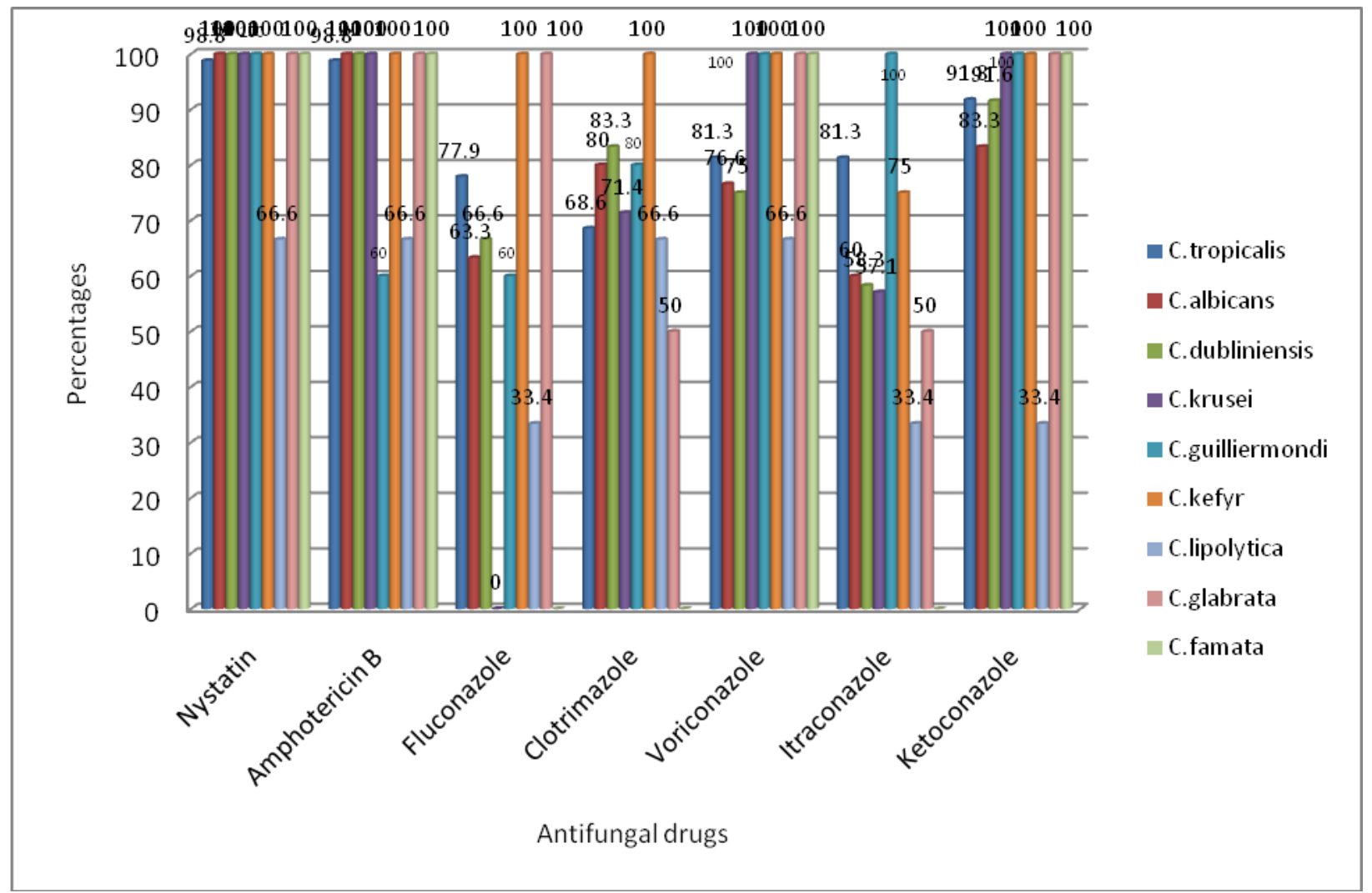

Figure.7 Antifungal resistance pattern of candida species

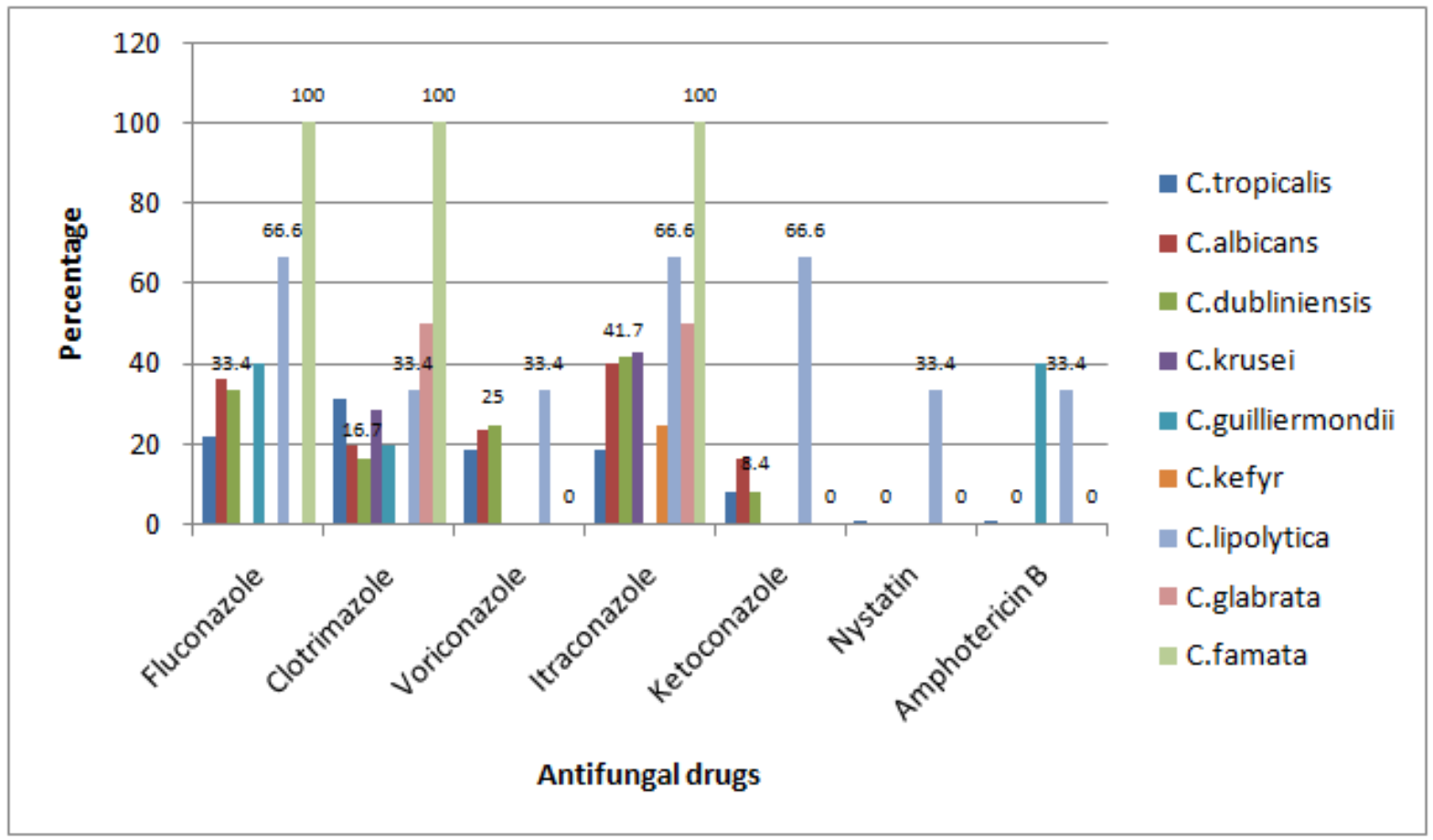


In the present study, C.albicans showed $100 \%$ susceptibility to Amphotericin B \& Nystatin which is in concordance with Vijaya et al., 2011, Shivanand et al., 2011, Ragini et al., 2011, Mondal et al., 2013, Ayesha Aslam et al., 2015, Parvez Anwar Khan et al., 2015.

C.albicans showed $36.6 \%$ resistance to Fluconazole which is in concordance with Ragini et al., 2011, Jayalakshmi et al., 2014 and Jayapriyasu kumaran et al., 2012.

To conclude, the present study showed that incidence of non-albicans Candida were higher from various clinical specimens. An increase in the predisposing conditions has resulted in an increasing incidence of nonalbicans Candida infections. Some of the Non-albicans Candida species is intrinsically resistant to commonly used antifungal drug like Fluconazole. Therefore, early speciation of Candida isolates along with their antifungal susceptibility tests not only will restrict the empirical use of antifungal agents but also greatly influence the treatment options for the clinicians and thus will be beneficial for the patients. The present study highlights the need for periodic surveillance of antifungal susceptibility pattern of the prevalent Candida species, as it would enlighten the judicious use of antifungal drugs in patients and thus preventing the emergence of drug resistance.

\section{Acknowledgements}

We sincerely thank Dr.Arif pasha M.D. Intensivist and Dr.Haritha M.D. Dermatology, NRI General hospital and the staff of all ICU's, department of dermatology, medicine, surgery, pediatrics, gynecology , ENT for their kind concern and co-operation in giving patients history and treatment details, collecting samples during the study period. I also thank Mrs.Saritha, Lecturer in statistics for helping me carry out statistical work and each and every staff of Department of Microbiology, NRI Medical College for their help and cooperation.

\section{References}

Anurag Malani, JareerHmoud, Loretta Chiu, Peggy L. Carver, Andrew Bielaczyc, and Carol A. Kauffman. 2005.Candida glabrataFungemia: Experience in a Tertiary Care Center. CID, 41(1): 975-981.

Arunaloke Chakrabarti. M.R. Shivaprakash. June 2008. Medical Mycology Laboratory Procedures. yeast identification, (Modified) ICMR, New Delhi, printed at sathya deep offset printers Pvt. Ltd. Chandigarh. pp 52-69.

A.Bandi, R., Kumar, S., Nirkhiwale, N., Pahwa. 2014. Species distribution and drug susceptibility of Candida in clinical isolates from a tertiary care centre at Indore. Indian $J$. Medi. Microbiol., Vol.32, No.1, pp 44-48.

Almeida, A.A., Mesquita, C.S.S., svidzinski, T.I.E, Oliveira, K.M.P.S. 2013. Antifungal susceptibility and distribution of Candida spp. Isolates from the University Hospital in the municipality of Dourados, State of Mato Grosso do Sul, Brazil; Rev. Soc. Bras. Med. Trop., 46: 335-339.

Abi-Said, D., Anaissie, E., Uzim, O., Raad, F., Pinzcowski, H., Vartivarian, S. 1997. The epidemiology of hematogenous candidiasis caused by different Candida species. Clin. Infect. Dis., 24: 1122-8.

Agarwal, J., Seema, B., Mallik, G.K., Jain, A. 2004. Trends in neonatal septicemia: Emergence of non-albicans Candida. Indian Pediatrics., 41: 712-15.

Amar, C.S., Ashish, J., Vinay Hajare, Sreekantha. 2013. Study of prevalence and antifungal susceptibility of candida. Int. J. Pharm. Bio. Sci., 4(2): (B) $361-381$.

Ayesha Aslam, NaeemAkhtar, FarihaHasan and Aamer Ali Shah. 2015. Prevalence and in vitro Antifungal Susceptibility Pattern of Candida species in a Tertiary Care Hospital, Rawalpindi, Pakistan. Pakistan J. Zool.; vol. 47(2), pp. 335-342.

Basu, S., Gugnani, H.C., Joshi, S., Gupta, N. 2003. Distribution of Candida species in different clinical sources in Delhi, India, and proteinase and phospholipase activity of Candida 
albicansisolates. Rev. Iberoam. Micol., 20: 137-140.

Baradkar, V.P., Mathur, M., Kumar, S. 2010. Hichrom candida agar for identification of Candida species. Indian J. Pathol. Microbiol., 53: $93-5$.

Chander, J. 2009. A text book of Medical Mycology, Candidiasis. $\quad 3^{\text {rd }}$ ed.New Delhi: Mehta Publishers, pp. 266-90.

Chakrabarthi, A., Ghosh, A., Batra, R., Kaushal, A., Roy, P., Singh, H. 1996. Antifungal Susceptibility pattern of non -Candida albicans and distribution of species isolated from Candidaemia cases over a 5 year period. Indian J. Med. Res., 104: 171-6.

Chakrabarthi, A., Mohan, B., Shrivastava, S.K., Marak, R.S.K., Ghosh, A., Ray, P. 2002. Change in the distribution and antifungal susceptibility of Candida species isolated from Candidaemia cases in a tertiary care centre during 1996-2000. Indian J. Med. Res., 116: 512.

Clinical Laboratory Standards Institute (CLSI). 2009. Method for antifungal disk diffusion Susceptibility testing of Yeasts; Approved Guideline- second edition. CLSI document M44-A2 (ISBN 1-56238-703-0). Clinical Laboratory Standard Institute, Wayne: Pennsylvania;

Colombo, A.L., Guimaraes, T. 2003.Epidemiology of hematogenous infections due to Candida spp. Rev. Soc. Bras. Med. Trop., 36: 599-607.

Cuetara, Alhambra, Del Palacio. 2006. Traditional microbiological diagnosis for invasive candidiasis in critical non-neutropenic patients. Rev. IberoamMicol., 23(1): 171-7.

Chakrabarti, A., Shivaprakash, M.R. 2005. Microbiology of systemic fungal infections. $J$. Postgrad. Med., 51: 16-20.

Chakrabarthi, A., Singh, K., Das, S. 1999. Changing face of nosocomial candidaemia. Indian $J$. Med. Microbiol., 17(4): 160-6.

Fridkin, S.K., Kaufman, D., Edwards, J.R., Shetty, S., Horan, T. 2006. Changing incidence of Candida Bloodstream infections among NICU patients in United States: 19952004.Pediatrics; 117: 1680-87.

Forbes, B.A., Sahm, D.F., Weissfeld, A.S. 2007. Laboratory methods in basic Mycology. In: Bailey and Scottes Diagnostic Microbiology. 12th Ed. St. Louis: Mosby;:629-713.

Freydiere, A.M. 1996. Evaluation of CHROMagar Candida plates. J. Clin. Microbiol., 34: 20-8.

Filloti, Spiroglou, Roiliedes. 2007. Invasive candidiasis in pediatric intensive care patients:epidemiology, risk factors, management, and outcome, Intensive Care Med., 33(7): 1272-83.

Fridkin, S.K., Jarvis, W.R. 1996. Epidemiology of nosocomial fungal infection. Clin. Microbiol. Rev., 9(4): 499-511.

Farooqi, J.Q., Jabeen, K., Saeed, N., Iqbal, N et al., 2013. Invasive candidiasis in Pakistan: clinical characteristics, species distribution and antifungal susceptibility. J. med. Microbiol., 62: 259-268.

Geeta, S.H. 2014. Study of Characterization \&Antifungal susceptibility Testing Of Clinically Significant Candida Species. Journal Of Evolution Of Medical And Dental Sciences; Vol 3, Issue 22, June 02; Page: 5973-5978.

Hobson, R.P. 2003. The global epidemiology of invasive candida infections- is the tide turning ? J Hospinfect., 55: 159-168.

Hajjeh, R.A., Sofair, A.N., Harrison, L.H., Lyon, G.M., Arthington-Skaggs, B.A., Mirza, S.A. et al. 2004. Incidence of bloodstream infections due to Candida species and In Vitro susceptibilities of isolates collected from 1998 to 2000 in a population-based active surveillance program. J Clin Microbiol., 42: 1519-1527.

Sardi, J.C.O., L. Scorzoni, T. Bernardi, A.M. FuscoAlmeida. 2013. Candida species: current epidemiology, pathogenicity, biofilm formation, natural antifungal products and new therapeutic options. J. Med. Microbiol., 62: 10-24.

Jha, B.K., Dey, S., Tamang, M.D., Joshy, M.E., et al.,2006. Characterization of candida species isolated from cases of lower respiratory tract infection. Kathmandu University Med. J., Vol. 4, No. 3, Issue 15, 290-294.

Jabra-Rizk, M.A., Brenner, T.M., Romangnoli, M., Baqui, A.A.M.A., Merz, W.G., Falker, W.A. Jr, et al. 2015. Evaluation of a reformulated CHROMagarCandida. J. Clin. Microbiol. Zool., 39 -9.

Jayalakshmi, L., G. RatnaKumari, S.H. Samson. 2014. Isolation, Speciation and Antifungal Susceptibility Testing of Candida from Clinical Specimens at a Tertiary Care Hospital. Sch. J. App. Med. Sci., 2(6E): 31933198.

Jayapriya Sukumaran, Jeya Meenakshi Sundaram, Ranjith Raj Sivan. 2012.Changing trend in the Clinical Distribution of Candida Species in a Tertiary care hospital. J. Dr.NTR University of Health Sci., 1(4): 222-226.

Khan, Z.U., Ahmad, Mokaddas, E., Chandy, R. 2004. Tobacco agar, a new medium for 
differentiating Candida dubliniensis from Candida albicans. J. Clin. Microbiol., 42: 4796-8.

Koehler, A.P., Chuk, C., Houang, E.T.S., Cheng, A.F.B. 1999. Simple, reliable and cost effective scheme for the clinical laboratory. $J$. Clin. Microbiol., 37: 442-6.

Kojic, E.M., Darouiche, R.O. 2004. Candida infections of medical devices, Clin. Microbiol. Rev., 17: 255-67.

Lo, H.J., Ho, Y.A., Ho, M. 2001. Factors misidentification of Candida species. $J$. Microbiol. Immunol. Infect., 34: 171-7.

Lata, R., Patel, Jayshri, D., Pethani, Palak Bhatia, Sanjay D Rathod, Parul D Shah. 2012.Prevalence of Candida infection and its Antifungal susceptibility pattern in tertiary Care hospital, Ahmadabad.; Nat. J. Medi. Res., Vol. 2(4), 439-441.

Larone, D.H. 2002. Medical important fungi: A guide to identification, 4th ed. Washington DC: American society for microbiology press; Milne LJR. Fungi. In: Colle JG, Frase AG, Marmion BP, Simmons A. 2007. Mackie and McCartney Practical Medical Microbiology.14th ed. Edinburgh: Churchill Livingstone; 695-717.

Merz, W.G., Hay, R.J. 2005. Topley \&Wilson's Medical Microbiology and Microbial infections, Medical Mycology. Chapter - 1, 15, 30, 10th edition, Edward Arnold (Publishers) Ltd.,: 11, 256, 579-620.

Mirdha, B.R., Sethi, S., Banerjee, U. 1998. Prevalence of fungal species in patients with funguria. Indian J. Med. Res., 107: 90-3.

Mondal, S., Mondal, A., Pal, N., Banerjee, P., Kumar, S., Bhargava, D. 2013. Species distribution and in vitro antifungal susceptibility patterns of Candida. J. Institute of Med., 35:1;pp45-49

Narain, S., Shastri, J.S., Mathur, M., Mehta, P.R. 2003. Neonatal Systemic Candidiasis in a tertiary care centre. Indian J. Med. Microbiol., 21(1): 56-8.

Oksala, E. 1990. Factors predisposing to oral yeasts infections. Acta odontal scand,48: 71-74.

Odds, F.C. 1988.Candida and candidosis: A Review and Bibilography. $2^{\text {nd }}$ ed. London: BailliereTindall;

Parveen, N., Munir, A.A., Din, I., Majeed, R. 2008. Frequency of vaginal candidiasis in pregnant women attending routine antenatal clinic. $J$. Coll. Physicians SurgPak., 18(3): 154-7.

Pfaller. 1995. Epidemiology of candidiasis. Journal of hospital infection; 30(1):329-338.
Faller, P., M.A., Houston, A, Coffman S. 1996. Application of CHROMagarCandida for rapid screening of clinical specimens for Candida albicans,Candidatropicalis, Candida kruseiand Candida glabrata. J. clin. Microbiol., 34: 58-61.

Piyush Gupta, M.M.A. Faridi, S. Rawat and P. Sharma. 1996. Clinical Profile and risk Factors for Oral Candidosis in Sick Newborns. Indian Pediatrics, Volume 33, PP 299-303.

Peng, C.F., Lee, K.M., Lee, S.H. 2007. Characterization of two chromogenic media of Candida ID2 and CHROMagar Candida for preliminary identification of yeasts. J. Biomed. Lab. Sci., 19: 63-8.

Parvez Anwar Khan, Nazish Fatima, Nabeela, SarvarJahan. et al. 2015. Antifungal susceptibility pattern of Candida Isolates from a tertiary care Hospital of North India: A five year study. Int. J. Curr. Microbiol. App. Sci., special issue-1:pp.177-181.

Rippon, J.W. 1988. Medical Mycology: the pathologic fungi pathogenic actinomycetes.3rd ed. Philadelphia: WB Saunders,: 484-531.

RaginiAnanthKashid, SandhyaBelawadi, Gayatri Devi, Indumati. 2011. Characterisation and antifungal susceptibility testing for candida in a tertiary care hospital. J. Health Sci. Res., 2(2): 1-12.

Roy, R.C., Sharma, G.D., Barman, S.R, Chanda, S. 2013. Trend of Candida infection and antifungal resistance in a tertiary care hospital of northeast India. Afr. J. Microbiol. Res., 7: 3112-3116.

SarojGolia, K., Mallika Reddy*, K. Sujatha Karjigi and Vivek Hittinahalli. 2013. Speciation of Candida using chromogenic and cornmeal agar with determination of fluconazole sensitivity. Al Ameen J. Med. Sci., 6(2): 163166.

Agarwal, S., V. Manchanda, N. Verma, P. Bhalla. 2011. Yeast identification in routine clinical microbiology laboratory and its clinical Relevance. Indian J. Med. Microbiol., 29(2): 172-7.

Singhi, S.C., Reddy, T.C.S., Chakrabarthi, A. 2004. Oral Itraconazole in treatment of candidaemia in a paediatric intensive care unit. J Paed., 71: 973-6.

St-Germain, G., Laverdiere, M., Pelletier, R. et al. 2001. Prevalence and antifungal Susceptibility of 442 Candida Isolates from blood and other normally sterile sites: Results of a 2 Year (1996-1998) multicentric surveillance Study in Quebec, Canada. J. Clin. Microbiol., 39: 94995. 
Shyamala, K., Shettar, Asha, B., Patil, Shobha, D. Nadagir, T.A. Shepur. July-September 2012. Evaluation of Hicrome differential agar for speciation of candida. J. Acad. Medi. Sci., 101 Vol. 2, Issue 3, pp 101-104.

Sanjeev Kumar, AnamikaVyas, Mrityunjay Kumar, S.K. Mehra. 2013. Application of CHROMagarCandida for Identification of Clinically ImportantCandida Species and their Antifungal Susceptibility Pattern. Int. J. Biol. Med. Res., 4(4): 3600-3606.

Shivanand Dharwad, Saldanha Dominic R.M. 2011. Species Identification of Candida Isolates in Various Clinical Specimens with Their Antifungal Susceptibility Patterns J. Clin. Diag. Res., November (Suppl-1), Vol5(6):1177-1181.

Sulivan, D.J., Westerneng, T.J., Haynes, KA., Bennett, D.E., Coleman, D.C. 1995. phenotypic and molecular characterization of a novel species associated with oral candidosis in HIV-infected individuals. Microbiol., 141: 507-1521.

Salerno, C., Pascale, M., Contaldo, M., Esposito, V., Busciolano, M., Milillo, L. 2011. Candidaassociated denture stomatitis. Med. Oral. Patol. Oral Cir. Bucal., 16(2): e139-43.

Soysa, N.S., Samaranayake, L.P., Ellepola, A.N. 2006. Diabetes mellitus as a contributory factor in oral candidosis. Diabet. Med., 23(5): 455-9.

Segal, E., Elad, D. 2007. Candidiasis. In: Merz WG, Hay RJ, Topley Wilson 's - Microbiology and microbial infection. 10thed. Medical mycology: London: Hodder Arnold;: 579-613.

Sahni, V., Agarwal, S.K., Singh, N.P., Anuradha, S., Sikdar, S., Wadhwa, A. et al. 2005. Candidemia an under-recognized nosocomial infection in Indian hospitals. J. Assoc. Physicians India, 53: 607-11.

Sachin, C.D., Ruchi, K., Santosh, S. 2012. In vitro evaluation of proteinase, phospholipases and haemolysin activities of Candida species isolated from clinical specimens. Int. J. Med. Biomed. Res., 1: 153-157.
Shivaprakasha, S., Radhakrishnan, K., Karim, P. 2007. Candida spp. other than Candida albicans: A major cause of fungaemia in a tertiary care centre. Indian J. Med. Microbiol., 25: 405-407.

Singhi, S.C., Reddy, T.C.S., Chakrabarthi, A. 2004. Oral Itraconazole in treatment of candidaemia in a paediatric intensive care unit. J. Paed., 71: 973-6.

Tejashree, A., Raghavender Rao, M., Rashmi, P. Mahale, Madhuri Kulkarni. et al. 2014. Speciation and Invitro Antifungal Susceptibility Testing of Candida isolates in various clinical samples in a Tertiary Care Hospital in South India; Int. J. Adv. Scientific and Technical Res., Issue 4 volume 5, pp 43844.

Uma Chaudhary, Antariksh Deep, Narender Chabbra, 2009. Rapid Identification and Antifungal Susceptibility Pattern of Candida Isolates from Critically Ill Patients with Candiduria. $J$. Infect. Dis. Antimicrob. Agents, 26: 49-53.

Vazquez, J.A., Sobel, J.D. 2002. Mucosal candidiasis. Infect. Dis. Clin. North Am., 16(4): 793-820.

Verma, A.K., Prasad, K.N., Singh, M., Dixit, A.K., Ayyagari, A. 2003. Candidaemia in patients of a tertiary health care hospital from north India. Indian J. Med. Res., 117: 122- 128.

Vijaya, D., harsha, T.R., Nagaratnamma, T. 2011. Candida speciation using chrom agar. J. clin. Diag. res., 5(4): 755-7.

Willinger, B., Manafi, M. 1999. Evaluation of CHROM agar Candida for rapid screening of clinical specimens for Candida species. Mycoses, 42: 61-5.

Yashavanth, R., Shiju, M.P., Bhaskar, U.A., Ronald, R. 2013. Candiduria: Prevalence and Trends in Antifungal Susceptibility in A Tertiary Care Hospital of Mangalore. J. Clin. Diag. Res., Vol-7(11): 2459-2461.

Yucesoy, M., Marol, S. 2003. Performance of CHROMagar Candida and BIGGY agar for identification of yeast species. Annals Clin. Microbiol. Antimicrobiol., 2: 1-8.

\section{How to cite this article:}

Naseema Shaik, Uma Penmetcha, Ramesh Babu Myneni, Padmaja Yarlagadda and Susmitha Singamsetty. 2016. A study of Identification and Antifungal Susceptibility Pattern of Candida species Isolated from Various Clinical Specimens in a Tertiary care Teaching Hospital, Chinakakani, Guntur, Andhra Pradesh, South India. Int.J.Curr.Microbiol.App.Sci. 5(7): 71-91. doi: http://dx.doi.org/10.20546/ijcmas.2016.507.006 